\title{
Developing New Software for Determination of Concrete Compressive Strength of the Existing Reinforced Concrete Buildings
}

\author{
Gamze DOGAN, Musa Hakan ARSLAN, Ahmet OZKIS, Murat CEYLAN \\ Konya Technical University
}

\begin{abstract}
Ability to determine the compressive strength of the concrete used at existing reinforced concrete buildings according to the traditional destructive methods is a quite timeconsuming, costly and difficult process. As for the non-destructive methods, they are in general not preferred due to their high error shares. Therefore, it is extremely important to develop a practical method and the software related hereto. It is aimed that compressive strength determination-oriented software study to be developed to be the first in the literature, reinforced concrete used in existing buildings using Image Processing Technical (IPT) and Artificial Neural Networks (ANN) together. For experimental study, 192 concrete core samples were produced from 32 different sets of concrete block. Concrete surficial images and compressive strength of the core samples are matching. The 192 concrete core samples images were digitized with IPT and were used ANN for training and test set. 27 images of concrete samples for validation process (validation set) selected randomly from reinforced concrete building. Even though results from samples produced in laboratory is quite satisfactory, results from the case samples obtained from real existing RC buildings is not reached the desired level.
\end{abstract}

Keywords: Reinforced Concrete Building, Concrete, Core, Non-destructive Methods, Image Processing, Artificial Neural Network

\section{Introduction}

Determining the compressive strength of concrete in existing buildings is a time consuming, costly and difficult process. The method known as the most accurate method for determining the compressive strength of concrete in the existing reinforced concrete buildings is the method of coring. Damage to the concrete mass when the core is taken and the time-consuming evaluation phase take the disadvantage of this method. In this 
study, a method that can be applied easily, with low cost and fast results, can give results as close as possible to the core results (high accuracy rate) is presented. With this study, compressive strength of concrete in existing structures can be determined easily by using artificial intelligence methods (Image Processing Technique and Artificial Neural Networks).

\section{Methods}

According to the different parameters effecting the concrete compressive strength, 32 concrete mass were produced such that 6 cores samples could be taken from each one of them (total of 192 core samples could be taken). The dimension of the concrete masses produced schematically is given Figure 1.
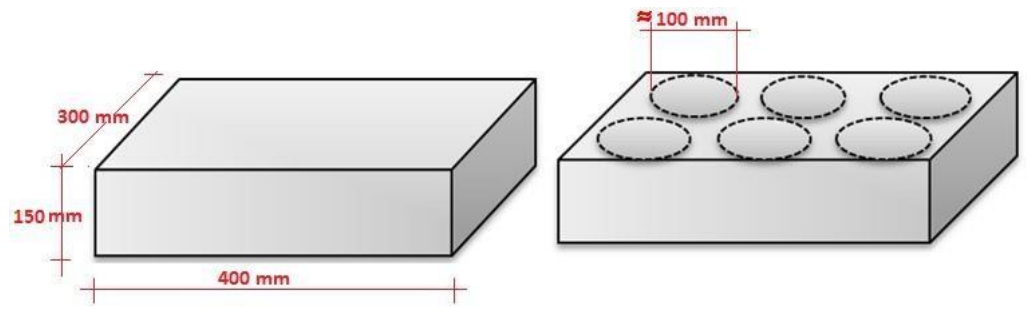

Figure 1. Schematic representation of produced concrete masses samples)

The images of core surfaces are taken under equal conditions. Imaging and coring process for concrete mass is shown in Figure 2 schematically.
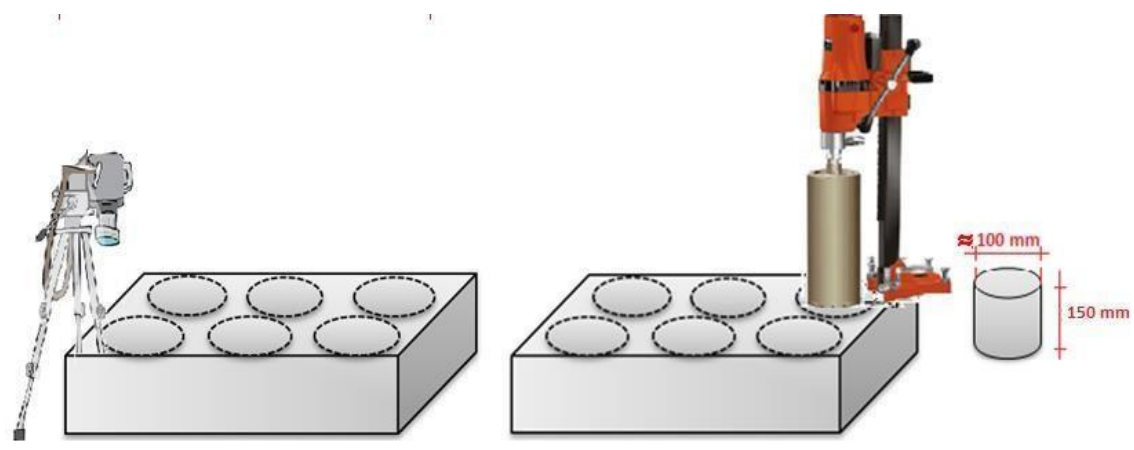

Figure 2. Schematic representation of photographing and taking of core samples on concrete mass 
The surface images of 6 core samples were taken from each of the 32 different concrete masses and the data set was prepared for the analytical study. Figure 3 shows the surface images of the different coring area. Figure 4 shows the process of coring sample. The core samples are shown in Figure 5.

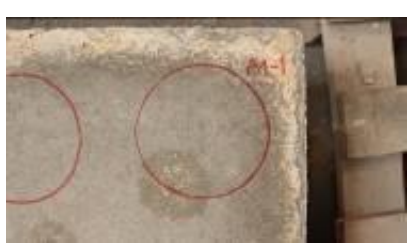

Surface image of the Surface image of the Surface image of the sample A1-1 sample A1-3 sample A1-4

Figure 3. Some examples of surface imaging of concrete mass before coring
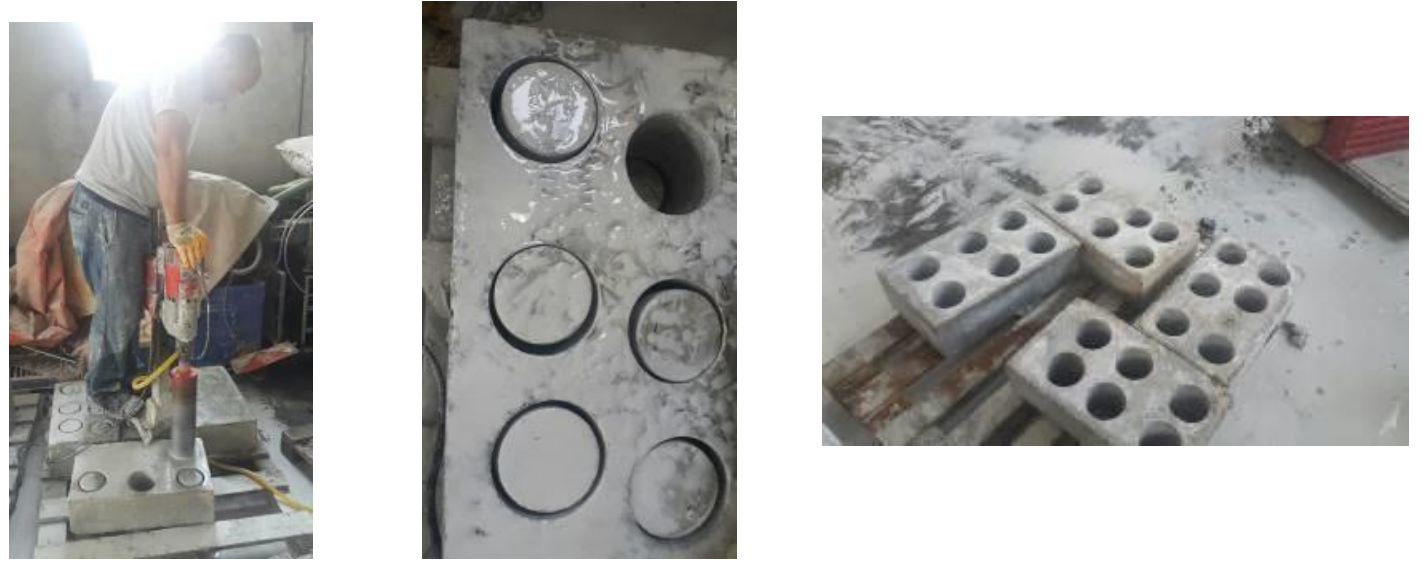

Figure 4. Coring process from concrete masses
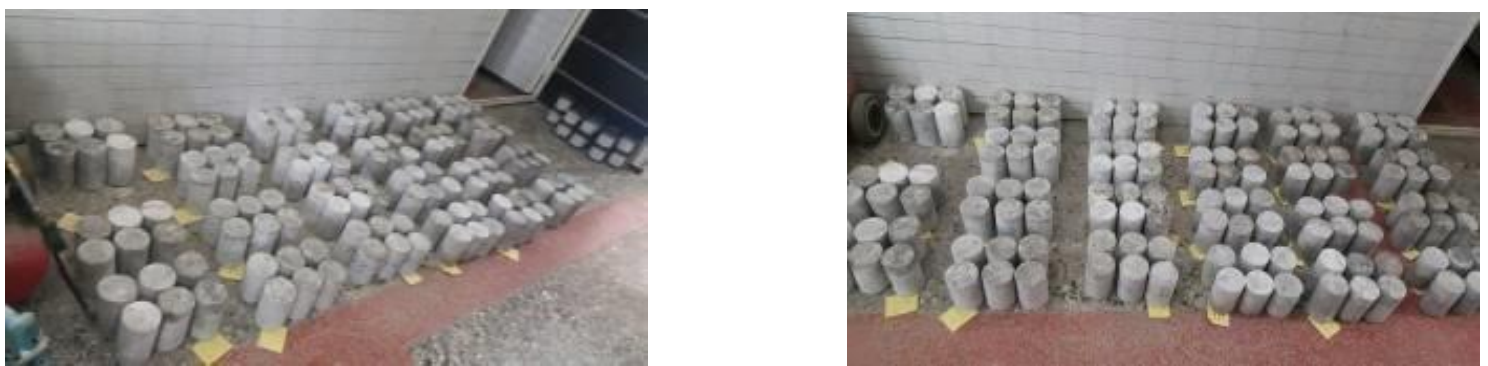

Figure 5. Core samples from concrete masses

Core samples were subjected to uniaxial vertical loading by hydraulic press. Obtained results as test data set used for network training in artificial neural networks (ANN). After the training, different core samples were taken for the validation set. These core samples 
(validation set) were taken from 6 different existing reinforced concrete structures. The coring and imaging processes of the structure are shown in Figure 6 step by step.
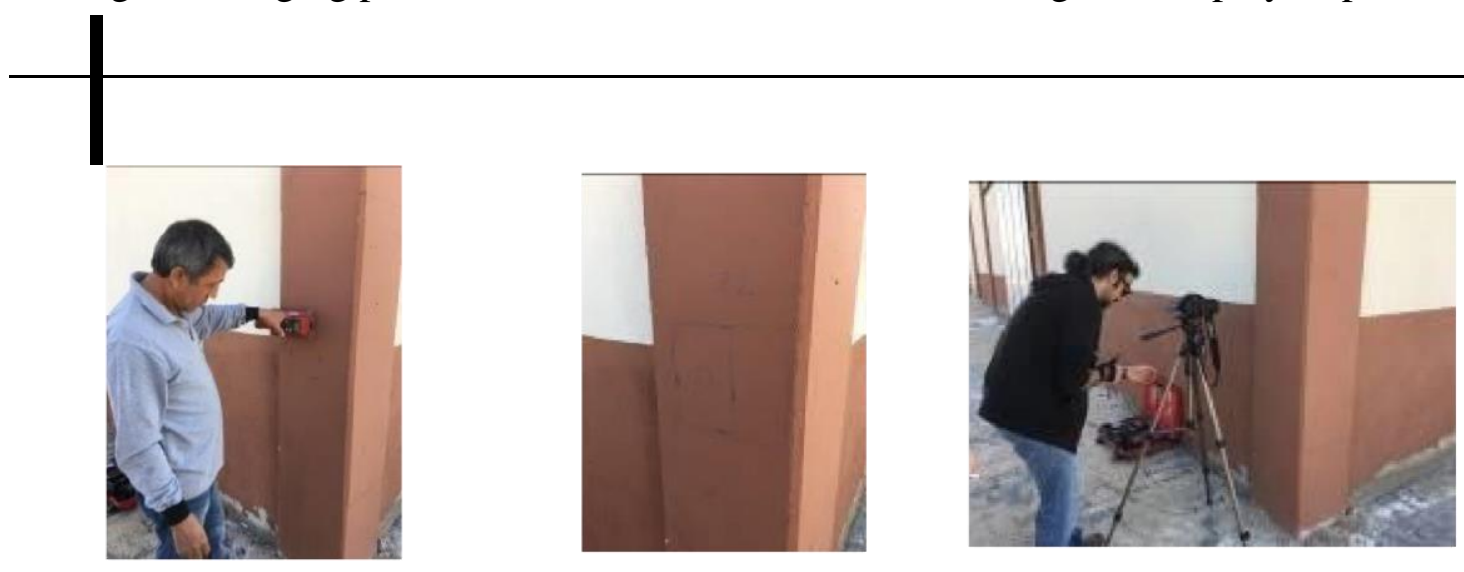

1. Detection of the coring

2. Marking core area

3. Camera setup for imaging area
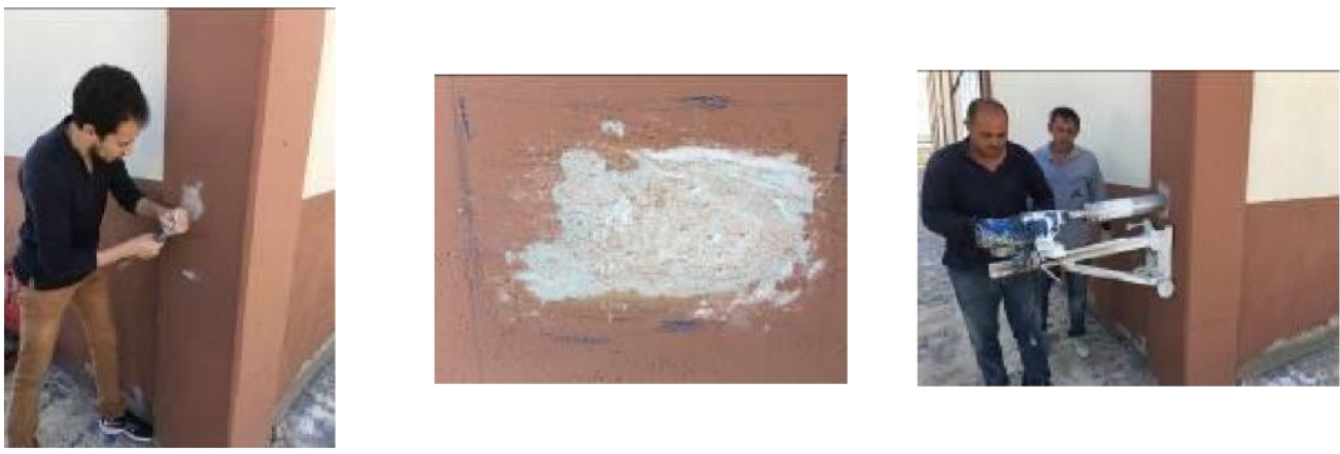

4. Stripping paint and plaster on

5. Imaging of concrete

6. Cores taken from the column the column surface

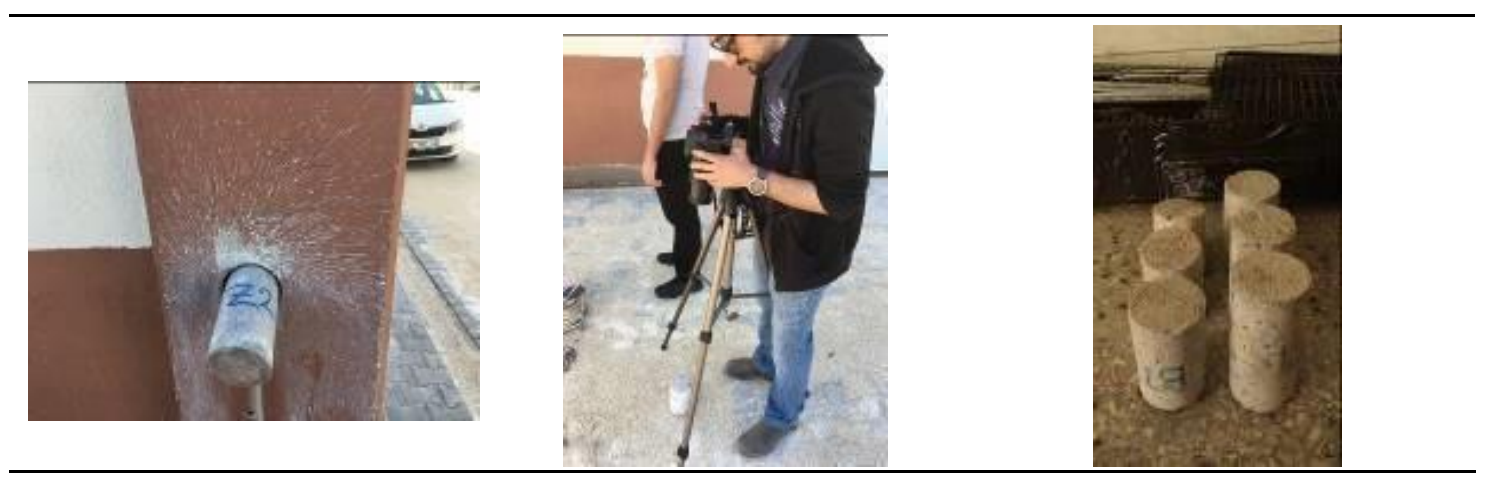

7. Removal the core sample

8. Imaging the surfaces of 9 . The samples are prepared by ${ }^{\text {core }}$ samples

bringing them to the laboratory environment. The samples are 
subjected to uniaxial compressive test with hydraulic presses and result values are noted.

Figure 6. Coring and imaging of concrete surface procedures from the existing structure

Images of concrete surfaces (from concrete mass) are transformed into a matrix form by MATLAB's image processing functions. The obtained matrices formed the ANN input data. The compressive strength values obtained from the experimental tests were matched with the models in the matrix form on the images using IPT and ANN and the system training process was started. In the ANN structure, ANN model was created from 3 layers, the digitized image data as the input layer, single hidden node layer as the hidden layer and the estimated compressive strength of concrete as the output layer. ANN model in MATLAB is shown in Figure 7.

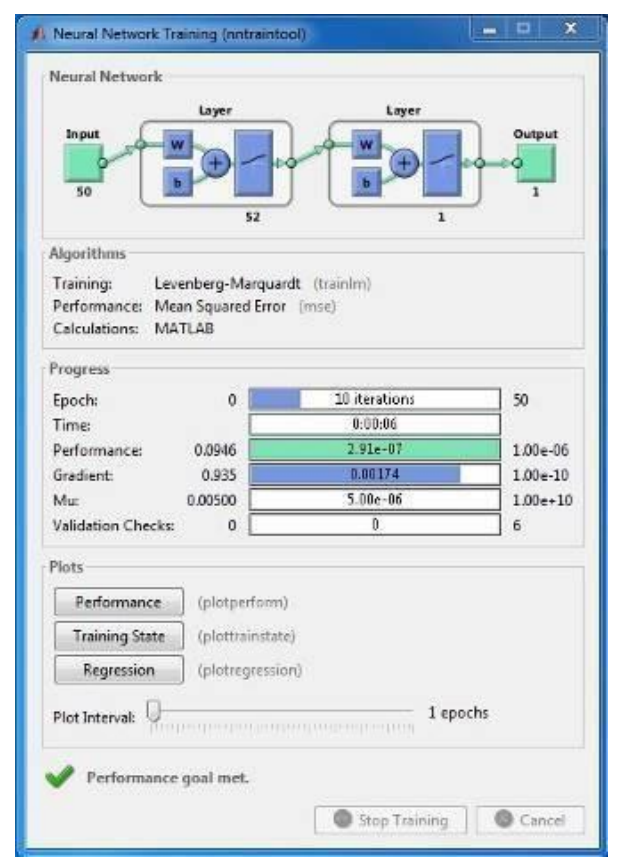

Figure 7. ANN model and its properties in MATLAB environment

\section{Results}

It is seen that if the error rate is kept in $30 \%$ of the 192 sample results in the laboratory, the accuracy rate will be between 70-75\%. The compression strengths of 27 core samples from 6 different buildings were tested by using analysis method (ANN and IPT). 
Although the obtained results according to the produced samples in the laboratory were quite satisfactory, it was seen that the success rate obtained from the concrete samples taken from the field (existing buildings) decreased below $50 \%$ for the verification set. 